\title{
Social Media and Students' Wellbeing: An Empirical Analysis during the Covid-19 Pandemic
}

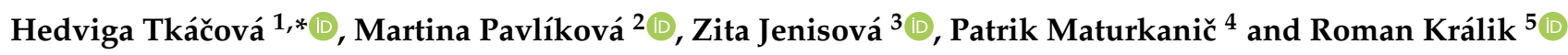 \\ 1 Department of Journalism, Faculty of Arts and Letters, Catholic University in Ruzomberok, \\ 03401 Ruzomberok, Slovakia \\ 2 Department of Journalism, Faculty of Arts, Constantine the Philosopher University in Nitra, \\ 94974 Nitra, Slovakia; mpavlikova@ukf.sk \\ 3 Department of Chemistry, Faculty of Natural Sciences, Constantine the Philosopher University in Nitra, \\ 94974 Nitra, Slovakia; Zjenisova@ukf.sk \\ 4 College of Applied Psychology, 41155 Terezín, Czech Republic; patrikmat@seznam.cz \\ 5 Department of Russian Language, Peoples' Friendship University of Russia (RUDN University), \\ 117198 Moscow, Russia; roman.kralik73@gmail.com \\ * Correspondence: hedwiga.tkacova@gmail.com
}

Citation: Tkáčová, H.; Pavlíková, M. Jenisová, Z.; Maturkanič, P.; Králik, R. Social Media and Students' Wellbeing: An Empirical Analysis during the Covid-19 Pandemic. Sustainability 2021, 13, 10442. https://doi.org/ $10.3390 /$ su131810442

Academic Editors: Valeria Bellisario and Giulia Squillacioti

Received: 31 July 2021

Accepted: 17 September 2021

Published: 18 September 2021

Publisher's Note: MDPI stays neutral with regard to jurisdictional claims in published maps and institutional affiliations.

Copyright: (c) 2021 by the authors. Licensee MDPI, Basel, Switzerland. This article is an open access article distributed under the terms and conditions of the Creative Commons Attribution (CC BY) license (https:// creativecommons.org/licenses/by/ $4.0 /)$.

\begin{abstract}
Various forms of social media (SM) appear to be very popular among young people because they provide information and entertainment, including a wide range of web technologies such as blogs, wikis, online social networks, and virtual networks. SM plays a huge role in the lives of children and teenagers, especially during the COVID-19 pandemic, when the computer becomes not only a means of entertainment or leisure, but also a necessary and everyday means of education and communication with other people. Thus, COVID-19 has brought a radical change, not only in the daily schedule and leisure time of pupils and students, but also in the perception of the procedures used by this specific group in the online space. Through our own research, using structured interviews and a questionnaire, we examine the use of SM as a tool to promote sustainable well-being in a group of high school students from various schools in central Slovak Republic (formerly Czechoslovakia). The research confirms that during the pandemic, the use of SM by the young respondents contributes significantly to well-being. This is the case when SM is used by high school students as a tool in promoting: (1) personal interests; (2) motivation; (3) communication and interpersonal connectivity; (4) preferred forms of online education; and (5) online games. The article presents a set of recommendations regarding the use of SM as a tool for sustaining the well-being of young people during the pandemic.
\end{abstract}

Keywords: COVID-19 pandemic; high school students; human well-being; Slovak Republic; social media; social media management; sustaining well-being

\section{Introduction}

COVID-19 (SARS-CoV-2) has definitely caused a shift in the perception of audience practices online. Changes will have an impact on content in both the new media [1] and social media (SM) [2], as well as an impact on communication studies [3] and media discussion [4]. It is also likely that, due to the increased use of new SM [5], there will likely be a decline in the use of traditional media and formats, etc. [6]. That is not to say that audience studies do not regularly analyse social patterns in media practices and discuss their consequences; however, the fact is, COVID-19 has affected and continues to affect an exceptionally high proportion of the population. It has changed people's perception of quality of life, as well as overall satisfaction and well-being. Therefore, as Petrovič and Murgaš point out, there is, unsurprisingly, a growing interest in public debate as well as researchers' interest in a part of the concept of quality of life, which deals with people's well-being, welfare, and happiness [7]. According to Parker and Igielnik from the Pew 
Research Centre, COVID-19 has reshaped the social, political, and economic landscape of many countries where, inter alia, Generation Z (today's high school students) "now peers into an uncertain future" [8].

The popularity of SM has grown rapidly, especially among young people in recent years [9-12]. It has become an integral part of the increasingly "social landscape" known as "the Internet" $[13,14]$. Despite this obvious interest, there seems to be a limited understanding of exactly what the term "social media" means. According to Kaplan and Haenlein, SM can be classified based on application. Thus, authors create more specific categories of SM and distinguish them as follows: collaboration projects, blogs, content communities, social networking sites, virtual game worlds, and virtual social worlds [15]. We can perceive an interesting phenomenon in the above classification of SM: they are a part of numerous aspects of our daily existence, and they have simply continued a trend that was there even before the pandemic.

When using SM, people observe other people, make new friends, expand their network, edit and update content, blog, post, share files, respond, tag, etc. This has been described by Jenkins et al. by the term "participatory culture" [16], because users are increasingly involved in creating web content, as well as consuming it [14]. Thus, today, experts have no doubt about the multiple impacts of SM on a person's lifestyle $[17,18]$. They prove, for example, that SM refines how respondents think, interact, and communicate their social lifestyle $[19,20]$, and they also discuss how SM can change people's healthy lifestyle habits [21-23]. Researchers are also interested in the use of SM and its impact on peoples' social behaviour [24,25], or their effects on social relationships [26,27].

Social media management utilizes "user-generated content" similarly to the context of brand management, which involves the social sharing of content from people (i.e., clients) who showcase brand loyalty. Thus, user-generated content is about brand building, brand communication, and trust building, which also has an effect on the satisfaction of people (i.e., current and potential customers) and their well-being.

Moreover, the social media analysis of Zamarreño-Aramendia, et al. proved that, in various contexts and cases (for example, in natural disaster prevention), SM is not used as a preventive element, but mostly only as a live information channel through which information is provided to the public. Thus, we agree with experts that the need to investigate closely how we can use SM as a tool to inform as well as to actively sensitize citizens is, generally speaking, proactive in prevention [28]. For example, SM can be used to raise awareness regarding the production of waste materials, the use of plastic materials, the prevention of environmental pollution, conservation resources, as well as the prevention of pandemic-related anxiety and stress, which similarly influence people's wellbeing. It is necessary to ask how we can manage current reactive social media management methods in order to strengthen their use in a proactive capacity.

In the last decade, research has focused on perceptions of quality of life in relation to SM [29-31], and research into overall satisfaction and well-being under their influence is still increasing [32-42]. The latter-mentioned took on completely new contexts during the COVID-19 pandemic, when changes in SM use and people's health behaviour [43-45] —and particularly mental health behaviours $[33,46,47]$ - were especially reported. Throughout the article, we will use the term "well-being" in the context of the COVID-19 pandemic as a term to denote the benefits that can be associated with the use of SM (for example, in developing personal interests or interpersonal connectivity) in the context of the relationship between those who used SM to derive benefits for well-being. In the context of the COVID-19 crisis, increased attention should be paid to online education with the use of SM. Education and online education, both in terms of developing competences such as knowledge, abilities, or skills, are all relevant to sustainable development and the attitudes that help us to make responsible decisions [48]. According to Kobylarek, there were two important aspects of education during the pandemic: technological challenges, in the form of the necessity of expanding the repertoire of the technical means of education; and social challenges, in the form of the need to rebuild relationships [49]. 
We will use the term "e-learning" in the article as a term to signify: (a) the educational process, i.e., the process used by the Internet to increase the effectiveness of traditional distance learning practices; (b) a set of tools to support the educational process; (c) and a communication platform, within which there is interaction between teachers and participants (transfer of knowledge and experience), as well as between participants in education (exchange of knowledge and experience, cooperation, etc.), i.e., mainly on the basis of synchronous online education.

Our goal is to reflect upon the effects of SM on the well-being of young people. Social media technologies seem to be very popular among young people, as they provide them with necessary information and entertainment. Using SM is natural, popular, and unpretentious for young people. This is one of the reasons why experts point to the daily use of social media by young people, and at the same time, have no doubt about the impact of it on their lifestyle and perceptions of well-being. In the first part of the article, we present the relevant literature and research which has been consulted, focusing particularly on the SM currently used by young people. In our opinion, the topicality of this issue is growing with regard to specificity; i.e., the sensitivity and vulnerability of the young generation.

Secondly, the paper presents our own current research. Using structured interviews $(n=20)$ in the first phase of the research, and questionnaires $(n=90)$ as a main research method, we examine the most numerous statements that can be identified as Slovak high school student's opinions regarding the use of SM as a tool for sustaining their well-being during the COVID-19 pandemic. The research sample consists of high school students from various schools in central Slovak Republic. The main aim of the study was to research the potential of SM as a tool for sustaining the well-being of the high school students under research during the pandemic. The research confirms that, from the point of view of young respondents in the time of COVID-19, SM really does constitute as a tool that contributes to the acquisition of personal well-being. This is the case when the students use SM as a tool to promote: (1) personal interests; (2) motivation; (3) communication and interpersonal connectivity; (4) preferred forms of online education; and (5) online games.

The present study attempts to form a small contribution to the hitherto sparse research about the use of SM as a tool for sustaining well-being during the pandemic. Despite being a research sample from a small county in Eastern Europe, the article presents a set of recommendations concerning the use of SM among young people, which can be an inspiration to consider the benefits of using SM as a tool for sustaining the well-being of users during a pandemic.

\section{Related Literature}

Information regarding relevant research was taken from a wide range of databases, such as Scopus, Web of Science, Science Direct, Wiley, Google Scholar, etc., to comply data collection with reliability indexed journals and databases. Related literature is presented with respect to the effects of SM on well-being. As a result, the following text is divided based on negative research findings, and the ambivalent or positive effects of SM on well-being.

First of all, Swist et al. examined literature published since 2010 on the use of SM by children and young people, and the effects on their well-being. They find that, from the age of five, nearly all of the children researched regularly access the Internet, and are spending more and more time online through a mobile device or phone that makes their access more personalised and frequent [50]. Similarly, O'Reilly et al. provided a thematic analysis of 54 adolescents aged 11-18 years, and proved more negative results. Adolescents in his research sample perceived SM as a threat to mental well-being, i.e., for some adolescents, it caused mood and anxiety disorders [43]. Likewise, McDool et al. proved the negative effects of SM, and specifically social networks, on young people. With the use of a large representative sample of 10-15-year-olds from the UK, experts proved that spending more time on social networks reduced respondents' satisfaction within all aspects of their lives; one exception to these research findings was their friendships [51]. Accordingly, other 
experts showed that, while face-to-face social interactions enhance well-being, overall, the use of social networks was negatively associated with well-being. This result was confirmed, inter alia, by research of data from 5208 subjects in the nationally representative Gallup Panel Social Network Study survey [52]. Finally, Cleave et al. pointed out in their research that SM is essentially used as a tool to promote local services, political information, or advertising, which can also be considered as negative. However, experts consider it a big mistake that current SM shows a limited interaction with the audience [53].

Furthermore, the use of SM during adolescence is associated with poor sleep quality, anxiety, and depression [54], with a decline in subjective well-being [55] as well as hyperactivity disorder, as SM is easily accessible and intensely stimulating [56]. Exposure to specific types of online content is associated with adolescents' aggressive behaviour, worse sexual relationships, body image problems, obesity, substance abuse [41], and loneliness [57,58].

It is interesting that more recent work has begun to change the initial negative view of the use of social media and its impact on well-being. Related research that focused on the ambivalent effects of SM on well-being is available in the study conducted by Bekalu et al. These authors noted that most studies were mistaken in measuring SM use and its effects in terms of dose-effect relations. For example, they note that previous studies have "focused on measuring frequency and duration of use, and have seldom considered users' emotional connections to SM use and the effects associated with such connections". The authors are convinced that previous studies are mistaken in thinking that the integration of SM use into people's social routines and their emotional connection to favourite websites is necessarily negative, which might bring a new view on this research issue [42]. Similarly, Frison and Eggermont assert that many studies with negative results regarding the use of social media on well-being in their research did not use a "differential approach to distinguish between different types of social networking site use", which they see as a mistake [57].

As stated in Allen's study, "SM elevate the ease in which individuals may form and create online groups and communities, but on the other, they can create a source of alienation and ostracism" [59]. The ambivalent results of this research are supported by the claims of Best, Manktelow, and Taylor, who researched the effects of SM on adolescent wellbeing in 43 original research papers. These authors also proved that the majority of studies reported either mixed or even no effect(s) of online social technologies on adolescent wellbeing [38]. As we have seen above, the issue of the relationship between social networking site use and well-being seems to be ambiguous and controversial, and research on this issue is faced with numerous challenges.

In the third place, regarding the positive effects of SM on well-being-including the positives of the amount of time spent in the SM environment-experts show that young people who use selected social networks report higher social capital in their school and online relationships [59], as well as social capital and self-esteem [60], health and health communications [61], or social capital and subjective well-being [62]. Valenzuela et al. find positive relationships between the intensity of Facebook use and students' life satisfaction, social trust, civic engagement, and political participation among college students throughout Texas $(n=2.603)$ [63]. This problem is also discussed in studies by other experts, who connect social network site use with perceptions of social support, stress, and well-being, and provide clear evidence that interpersonal social support impacts stress levels and, in turn, psychological well-being [64]. A study regarding the necessity of considering that SM allows various stakeholders to establish knowledge synergies, and thus helps to strengthen collective expertise and intelligence, is also fascinating [65]. The presentation of positive findings could be continued, although these are fewer than the negative results in the relevant research. At this point, we consider it more important to mention a clear controversy between the SM use and well-being issue.

The above-mentioned related research, including the latest research in the context of the COVID-19 pandemic, may be summarized as follows: During the pandemic, a dominant proportion of researchers focused on researching the symptoms of mental health disorders, which is shown in the studies of the many experts presented above [38,50,51,55-58,66-70]. 
In addition, Arora and Gray observe that only a small portion of research has focused on the effects of the pandemic on people's lifestyles or well-being [47]. Current research also limits the use of current media as a support and maintenance of well-being status, and, moreover, research often deals with only two or three social networks $[28,31]$.

This article aims to make a small contribution to the under-represented research about the use of SM as a tool for sustaining well-being during the COVID-19 pandemic. Media as a tool for sustaining well-being during the COVID-19 pandemic also forms a new research topic within this article.

\section{Methodology}

Firstly, we will briefly present the geographic location of this empirical study (Slovak Republic) in order to better contextualize the analysis. In 1993, after more than forty years of communist dictatorship, Czechoslovakia split into two independent states-the Czech Republic and Slovak Republic. This separation is well-known today as the "Velvet Divorce", due to its peaceful nature. Today, Slovak Republic is a member of the European Union, with a population of 5.5 million, and is considered to be one of the smallest landlocked countries in Eastern Europe.

As with other countries, Slovak Republic realized that, although the global COVID-19 pandemic closed our households, it opened the door to many activities, opportunities, and interests that people might find more interesting or attractive. The questions we are interested in are: what happens to young people and their feelings of well-being at a time when they are "hidden" behind their computer during the pandemic? Moreover, in which areas does the use of SM have any potential for sustaining the well-being of high school students from various schools in central Slovak Republic during the pandemic?

The main aim of the research was to study the potential of SM as a tool for sustaining the well-being of high school students in central Slovak Republic during the pandemic.

In this study, the students who were under research responded, both in person and online, to questions about their daily online activities. The research consists of two parts, which are shown in Table 1.

Table 1. Research design.

\begin{tabular}{cccc}
\hline Research Phase & Research Method & Research Sample & Research Criterion: Age \\
\hline 1st phase & Structured interviews & $\mathrm{n}=20$ & $15-20$ \\
2nd phase & Questionnaire & $\mathrm{n}=90$ & $15-20$ \\
\hline
\end{tabular}

Using structured interviews ( $n=20$; ages 15-20), in the first phase of the research, we examined the most numerous statements that could be identified as students' opinions about the use of SM as a tool for sustaining their well-being during COVID-19. The structured interview contained three areas that specified the subject of our interest, and thus narrowed the range of potential answers.

The structured interview examined the view of selected students on (1) personal interest in the social media environment during COVID-19; (2) SM as a tool for students' motivation in daily life during COVID-19; and (3) entertainment in the SM environment during COVID-19. The findings of this preliminary research were then implemented in a questionnaire, i.e., formulated questionnaire variables.

As the main part of this research, a specific self-administered questionnaire was used with the research sample ( $\mathrm{n}=90$; ages 15-20). The questionnaire consisted of 44 questions, incorporating a combination of fixed-choice and open-ended items, that create five main researched areas.

Researched areas consisted of data that were:

1. Subject to structured interviews (i.e., the first phase of the research);

2. Subject to content analysis of 60 public profiles of high school students on the social networking website Facebook (with the consent of the profile owners);

3. Partially supplemented data with related literature findings. 
Based on all findings, five research areas were formulated. The potential of SM as a tool for sustaining the well-being of high school students during the pandemic was examined in the context of:

(1) Personal interests;

(2) Student motivation;

(3) Communication and interpersonal connectivity;

(4) Preferred components of online study;

(5) Entertainment in the SM environment.

The questionnaire was administered via an online form in the period of JanuaryMarch 2021, which was the only solution due to the pandemic situation and the closure of schools. Research procedures were designed to protect students' privacy by allowing anonymous participation.

\section{Results}

Research into the potential of SM as a tool for sustaining the well-being of high school students from central Slovak Republic during the pandemic resulted in several interesting findings. Respondents were able to indicate more than one option, so the sum of their answers exceeds $100 \%$.

Through the questionnaire, wherein the first research area focused on the opinions of high school students, we can map students' favourite personal interests that they provide through SM. Our findings are shown in Table 2.

Table 2. Personal interests are sustained by using social media (SM) during the pandemic.

\begin{tabular}{cc}
\hline Researched Categories & Evaluation of the Variable \\
\hline Idea sharing platforms & $91.02 \%$ \\
Planning activities during the pandemic & $86.58 \%$ \\
Chatting via social networks & $83.25 \%$ \\
Watching movies & $77.7 \%$ \\
Listening to podcasts & $45.51 \%$ \\
\hline
\end{tabular}

Among the personal interests that respondents associate with a feeling of well-being (which is also feasible through SM during the pandemic), the most frequently mentioned item in the questionnaire were idea sharing platforms, in which high school students use Pinterest, Vimeo, and YouTube (91.02\%). The use of SM as a tool for sustaining the well-being of high school students is also shown in connection with planning activities during the pandemic (86.58\%). Additionally, students used SM during the pandemic to obtain information about opportunities for hiking, and were also interested in trail running, personal training, or reading. The third most frequently rated item in the questionnaire was chatting via social networks $(83.25 \%)$. Thanks to the open-ended questions of the questionnaire, we discovered that respondents mainly use Instagram, Facebook, Viber, and TikTok for chat. The fourth most rated item was watching movies (77.7\%), for which the research students used YouTube and Netflix streaming service during lockdown. Both of these sites are very attractive today for the public. The websites are popular video and movies sites, which provide open access (in the case of YouTube) as well as paid service (in the case of Netflix) to access a great number of videos and movies. Thus, they potentially have an important role in promoting well-being among young Slovaks. The research students' feeling of well-being is also evoked by listening to podcasts (45.51\%); personal interest is aroused especially by the podcasts How Stuff Works, Good Job, Brain!, and Here Be Monsters.

The second area of research focuses on respondents' motivations, which could, thanks to the use of SM, contribute to building and sustaining the well-being of students from central Slovak Republic during a pandemic. All findings are shown in Table 3. 
Table 3. Student motivation is sustained by using SM during the pandemic.

\begin{tabular}{cc}
\hline Researched Categories & Evaluation of the Variable \\
\hline Less of total time devoted to school after online education & $83.25 \%$ \\
Self-presentation, identity, and presence on social websites & $76.59 \%$ \\
Maintaining relationships through social networks & $75.48 \%$ \\
Time for hobbies & $73.26 \%$ \\
Availability of tutorials & $47.73 \%$ \\
\hline
\end{tabular}

At the pre-research stage, high school students stated that SM also helped to sustain their motivation during the pandemic. From the questionnaire conducted via the Internet and $\mathrm{SM}$, the respondents stated that they especially enjoy and positively evaluate the smaller amount of total time devoted to school after online education $(83.25 \%)$. Qualitative statements made during structured interviews within the pre-research similarly indicated that a large number of school projects and homework are conducted on the computer for students during the pandemic. One respondent stated "So, it's not about 'hand-made' and time-consuming school projects, but about computer-generated tasks that we get done faster." Another student also highlights the fun in creating school projects "thanks to working with a computer." Self-presentation, identity, and presence on social websites also evoke well-being among students, which is confirmed by the second most frequently mentioned item $(76.59 \%)$. Qualitative results obtained through structured interviews indicate students ${ }^{\prime}$ motivation and joy in sharing popular outdoor activities during a pandemic, so that "other people can be inspired." Students also have a sense of well-being when writing personal messages and creating statuses, as they give them the feeling of being "part of the world"; that they "experience the same as others"; "That in this (pandemic) they are not alone", and so on. In the two research categories just mentioned (i.e., "self-presentation, identity, and presence on social websites" and "maintaining relationships through social networks"), we can see that the online activities of users are in favour of building well-being, because young users feel part of online culture, or-in Jenkins's words-part of the "participatory culture" [16], where they are willingly involved in creating web content. Thus, the current research empirically proves that students' participation in online life directly correlates to their involvement online. The well-being of the individual, and at the same time, the motivation to use $\mathrm{SM}$, also causes a conscious maintaining of relationships through social networks (75.48\%); these are mainly Instagram, Facebook, and TikTok. The time that respondents devote to their hobbies on SM also contributes to the sustainability of students motivation by using SM during a pandemic (73.26\%). Even during the pandemic, high school students are engaged online in photography, yoga, and other activities, like the instructions for the production of jewellery, and so-called Live Animal Cameras, i.e., real shots of nature, which also contributes to the strengthening of their well-being. The fifth variable found is the availability of tutorials (47.73\%); respondents like Pinterest and DIY tutorials found on the Internet.

The third research area focuses on communication and interpersonal connectivity that might sustain the well-being of the researched high school students. All findings are shown in Table 4.

Table 4. Communication and interpersonal connectivity are sustained by using SM during the pandemic.

\begin{tabular}{cc}
\hline Researched Categories & Evaluation of the Variable \\
\hline Chat on social networks (meeting friends) & $97.68 \%$ \\
Social networks' closed groups (meeting family members, close friends) & $94.35 \%$ \\
Communication through smartphones & $93.24 \%$ \\
The SM communication tools (virtual communities, newsgroups, etc.) & $79.92 \%$ \\
New friends building and networking activities (meeting new people) & $13.32 \%$ \\
\hline
\end{tabular}

$\mathrm{SM}$ and related technologies are incredible tools for bringing people together and fostering connections when we are physically apart. They should be regularly used to build and maintain interpersonal connectivity. According to the students in our research 
group, communication during a pandemic takes place on several platforms. Interpersonal connectivity, which supports the well-being of high school students, most often takes place via chat on social networks $(97.68 \%)$, which respondents "use mainly to communicate with friends." According to the students, closed groups on social networks are a place where communication takes place with family members and close friends (94.35\%). The third most common item is communication by smartphone (93.24\%). The open questions of the questionnaire included a relatively wide list of benefits that respondents attribute to communication via smartphones; students especially mentioned voice communication, messaging, and ubiquitous wireless communication capability. In this regard, one can implicitly see the feeling of well-being, which respondents associate with the use of smartphones. Other possibilities that high school students use for communication and interpersonal connectivity are SM communication tools (such as virtual communities, newsgroups, blogs, or forums) (79.92\%), through which respondents meet and communicate not only with people they already know, but also with new people with whom they have a common problem or interest. We recorded surprisingly low values for the last item of the questionnaire; only $13.32 \%$ of respondents recorded the importance of making new friends and networking activities (meeting new people). In the preliminary research, this variable was created to examine how the respondents use SM to "establish new relationships" through them. The results suggest that, in our research sample, communication and interpersonal connectivity via SM during the pandemic do not focus on making new friends and networking activities through SM.

The fourth area of research focuses on students ' preferred components of online study, i.e., on the use of SM to acquire well-being during online education during the pandemic. In pre-research, four categories were identified. One category was supplemented from relevant research. All findings are shown in Table 5.

Table 5. Preferred components of online study through SM during the pandemic.

\begin{tabular}{cc}
\hline Researched Categories & Evaluation of the Variable \\
\hline Friendly interaction between teacher and students & $100 \%$ \\
Friendly interaction between students & $98.79 \%$ \\
Total time spent on online education & $96.57 \%$ \\
Clear and quick feedback between teachers and $\quad$ students [71,72] & $59.94 \%$ \\
Inspirational forms of online self-education & $46.62 \%$ \\
\hline
\end{tabular}

SM should be regularly used in creating sustainable and friendly interpersonal activity. This statement confirms our research findings, in which "friendly interaction between teachers and students" (100\%) proves to be the most common item, followed by "friendly interaction between students" (98.79\%). Based on the students' statements in the supplementary questions provided in the structured interviews (i.e., pre-research), it can be stated that the highest rated category (i.e., friendly interaction between teacher and students) is not seen by students as an impossible aim, even in the online space. One responded stated that "It's more complicated in the Internet because we don't meet at a library or by the elevator, but it's all the clearer that it's a mutual desire to spend time together." According to respondents, only the awareness of the pedagogue's efforts to spend time together with the students has meaning and value, despite the limitations that have occurred in connection with COVID-19. In the group of high school students, "total time spent on online education" can be seen in $96.57 \%$ of respondents. Less total time devoted by the respondents to the "school" is considered as a benefit that certainly contributes to well-being. According to one of the students from our pre-research, "the student is in the school as soon as he turns on the computer." The item "clear and quick feedback between teachers and students" was added to the questionnaire on the basis of the relevant research. Because "errors are made" during education [70], Deal considers clear and quick feedback as one of many examples of the advantage of online education for both students and teachers [71]. In our 
research sample, this item is considered as important by $59.94 \%$ of students. Finally, the item "inspirational forms of online self-education" ranks $46.62 \%$; students like, for example, educational podcasts or online visits to various cultural institutions, including theatres and museums.

In the questionnaire, the last research area focuses on student views on entertainment possibilities with the use of SM during the pandemic. In preliminary research, four categories were identified and one category was supplemented from relevant research. Our findings are shown in Table 6.

Table 6. Entertainment through the use of SM during the pandemic.

\begin{tabular}{cc}
\hline Researched Categories & Evaluation of the Variable \\
\hline Online games & $68.82 \%$ \\
Smart phone applications and games & $68.82 \%$ \\
Leisure on social media & $65.49 \%$ \\
Inspirational forms of online entertainment & $61.05 \%$ \\
Multimedia experience [72] & $53.28 \%$ \\
\hline
\end{tabular}

In the last research area, we can confirm that entertainment through SM contributes to the well-being of the respondents; our findings are shown in Table 6. Students from various schools in central Slovak Republic mainly prefer online games (68.82\%), because, as a respondent wrote in his questionnaire, "online games offer opportunities for our own identity performances, in an absolutely different reality". Qualitative statements by the respondents suggest that they perceive online games as a medium for fun or relaxation. The students mentioned other benefits of online games, especially "community and connection of like-minded people", i.e., game players. An equally popular item in this research area is the item smart phone applications and smart phone games (68.82\%). Entertainment with the use of smart phones brings respondents "a release of tension", "forgetting about the current situation (i.e., quarantine, isolation)", and in the words of some respondents, "time when they do not have to think about anything." The third most common item is leisure on social media $(65.49 \%)$; in this context, the respondents do not state any specific objective. We recorded inspirational forms of online entertainment in $61.05 \%$ of respondents, most of whom are interested in online concerts. The feeling of well-being among students is also evoked by the multimedia experience (53.28\%), which students experience thanks to iTunes, movies, animations, multimedia storytelling, etc.

\section{Discussion}

Exploring quality of life and related concepts of satisfaction, happiness, or well-being has been flourishing since the end of the 20th century [7]. In our opinion, the COVID-19 crisis brings a visible change. Although the effects of a pandemic on human well-being have not yet been comprehensively investigated, there are ever more professional opinions-as well as the results of public discussions-showing that, as the pandemic continues, different populations are at increased risk of experiencing diminished mental health. Experiencing feelings of stress and anxiety during a pandemic can worsen any existing mental health conditions an individual may have. Accessing necessary health care also seems to be a problem.

Our aim was to research the use of SM as a tool in sustaining the well-being of respondents from central Slovak Republic during the COVID-19 pandemic. Based on the findings in our research sample ( $n=20$ in pre-research, and $n=90$ in main research), several observations can be made:

(1) SM during the COVID-19 pandemic contributed to the well-being of respondents when they used it to support personal interests. Among personal interests, the items most mentioned in the questionnaire were idea sharing platforms, planning activities during the pandemic, and chat via social networks. We see that even during the pandemic, the informative function of SM predominates, for example, over the commercial func- 
tion [73], and proves to be of importance. In the context of the informative function of SM, young users can appreciate, for example, the frequency of website updates, information pages of various institutions, and, above all, the increasingly popular source of information-personal information pages of individuals (as sources of creative ideas and stimuli for adventure). We rank chat among the top communication options within SM, although at present, chat is already partially moving into the field of infotainment. It is evident that chat, as a popular Internet discussion, is increasingly influencing the nature of online entertainment (i.e., the entertainment function of $\mathrm{SM})$. Our research findings correlate with the findings of Lee and Ma, which prove that in the SM space, students are driven by gratification in seeking information and by socializing. Moreover, according to Lee, both of these desires subsequently lead students to sharing news via SM [74], which we consider to be very interesting.

(2) Secondly, SM during the pandemic contributed to the well-being of respondents when they were motivated by it. It is a fact that, in connection with the pandemic, there could be the danger of a decrease in the motivation of young people in many areas, such as their further education, sport activities, or hobbies, etc. Motivation seems to be a necessary factor, because it is a starting point for a responsible approach to one's personal growth, time-management, use of new technologies, education, self-management, etc. All the more interesting is the research by Neal, Wood, and Quinn, who found that people tend to perform up to $45 \%$ of the activities they perform constantly and out of habit during the day, i.e., in the same context. For example, reading a newspaper on the bus on the way to school, or visiting a fast food restaurant [75]. A pandemic represents a significant intervention in this "everyday life", which affects, among other things, the motivation of an individual in performing daily tasks, and an increase in negative emotions, including the perception of (un)wellbeing [76-78].

As our research group consists of high school students from various schools in central Slovak Republic, in an academic environment, we believe that serious problems can occur under the influence of broken stereotypes. Academic procrastination can occur in all kinds of everyday student tasks [79] and at all levels of education [80]. This can occur through a failure in self-regulated learning [81], which interferes with academic results [82-84], inter alia, by negatively affecting the student's ability to complete his/her tasks on time [85-87] and by significantly impairing academic performance [88]. Academic procrastination does not mean inaction, although this impression is often given. Although a procrastinating individual does not perform the tasks he should do, he has many other activities that he engages in and that occupy his time [89]. Procrastination is primarily a motivational problem that cannot be associated only with poor time-management skills or student laziness [90-93]. Research findings repeatedly confirm that if a student has internal motivation to perform compulsory tasks, they put them off less [93]. Self-motivation thus proves to be one of the key aspects in the prevention of academic procrastination [87], even in the difficult times of a pandemic. In this context, our own research findings are also growing in importance. The second area of research introduced a set of motivational factors that contribute to an increase of well-being among students from central Slovak Republic. Student motivation is sustained by the use of SM during a pandemic consists of: a decrease in total time devoted to school; self-presentation, identity, and presence on social websites; maintaining relationships through social networks; time for hobbies; and an availability of tutorials in the social media environment.

(3) One can agree with experts who say that SM appears to be a critical resource in helping individuals cope with the difficulties raised by the pandemic [94]. In the fourth area, we find that communication and interpersonal connectivity-which support the well-being of respondents during the pandemic - most often take place in the chat on social networks (meeting friends) and in closed group social networks (meeting family members and close friends). Communication and interpersonal connectivity—which 
support the well-being of high school students from central Slovak Republic during the pandemic - are ongoing through the use of smartphones, on which students appreciate voice communication, messaging, and ubiquitous wireless communication capability. Students also appreciate social media communication tools (for example virtual communities or blogs); however, surprisingly little in making new friends and networking activities happen through SM (i.e., meeting new people).

Surprisingly, in our research sample, communication and interpersonal connectivity on SM during the pandemic do not focus on 'making new friends' and networking activities (meeting new people), which agrees with the findings of several other experts. Authors Donath and Boyd are among the first to hypothesize that the online space may not increase the number of strong ties a person may have. On the contrary, they pointed out that, because of the technology which is easily used in maintaining these links, an individual's weak ties may increase [95]. Similarly, Quan-Haase and Young proved that SM is mostly used by young people to maintain their relationships with others, and with the aim of being acquainted with those who live near or far. Social networks especially make it simpler to communicate with multiple people at the same time. SM may also make it easier for users to monitor the activities of people and friends they have not seen in a while. Users also mentioned reconnecting with new or old friends [96]. To the third, other experts accordingly proved that the use of Facebook has a strong association with maintaining or consolidating existing, mostly offline relationships, as opposed to meeting new people [33].

(4) SM during COVID-19 contributed to the well-being of respondents when they were components of an online study. Experts draw attention to the expansion of the concept of e-learning, especially during the pandemic, which is related to the current development of SM and new technologies, and especially to the application of innovative approaches in the use of them in education. During the pandemic, L. Murphy considers distance learning as not necessarily synonymous with autonomous learning or isolated learning, even though in the past it has been seen in this way. Today's education, even in the pandemic, is less autonomous thanks to the technology that, according to Murphy, has potentially removed some of the most problematic aspects of distance education, for example: the physical separation of learners, or of learners and teachers; the possibility of the comparison of skills between students; or the lack of opportunity to develop interactive competences [92]. Basically, all of the aspects mentioned are part of our research findings in this research area. Online study is perceived by students from various schools in central Slovak Republic as a time for building well-being. This is because distance learning includes: friendly interaction between teacher and students; friendly interaction between students; less time spent on online education (compared with offline education); inspirational forms of online self-education; and an experience with clear and quick feedback between teachers and students. We can see that, despite the lack of personal contact, even during the COVID-19 crisis, an earlier observation can be confirmed that "the key to success was (and still is) good teacher-student contact, which technology can always facilitate." [48] Friendly interaction between teacher and students might encourage mutual personal esteem and respect to education as confirmed by Tvrdoň's research findings, which remind us that "if students respect and authority, they also respect the school rules" [97].

In the questionnaire, students further evaluated an item named 'inspirational forms of online self-education', and connect this item especially with the popularity of podcasts. We consider it interesting that the respondents argue in favour of their use in online education. It can be stated that the respondents would like to use podcasts to review lectures or understand the lesson content, especially when they had difficulty with understanding new content or terminology. These stimuli can also be seen as "guides" to increase the well-being of students in relation to current education. Thus, we can agree with Noor Al-Deen and Hendricks, who pointed out that SM can 
facilitate learning by enhancing students' engagement, identity, and enjoyment of a given course, independent of the content to be learned [98].

(5) Although there are divergences among experts about the good or bad, liberating or oppressive effects of online games on people, with special emphasis on children and young people, some of them are positive about the use of computer-aided writing and computer games. Moreover, some consider games as a good resource for children and young people, enabling them to play with different identities and to challenge expectations [97-100]. Thus, we can consider it to be positive that the online space provides access to pleasures only associated with online games, which is the most rated item among Slovak high school students in the last of our research areas. As stated in the questionnaire, "It's tempting, because online games and their new features offer opportunities for self-identity performances in a totally different reality". The qualitative statements produced another interesting finding. Students from central Slovak Republic perceive online games not only as a tool for fun or relaxation, but also for other benefits, such as "community and social connection of like-minded people", i.e., game players. This particular finding in our research correlates with Lufkin, who writes about "community connection on the other side of a screen". According to that author, young people, despite the fact that they are sitting for many hours alone, are not necessarily isolated. With the rise of SM, gamers have perfected the art of building communities in, as well as around, video games, so they "don't just compete with strangers on the Internet, but forge genuine, enduring friendships." [101,102].

In addition to online games, smartphone applications and games were also popular in the research sample. Entertainment with the aid of smartphones brings respondents "a release of tension", "forgetting about the current situation (i.e., quarantine, isolation)", and, in the words of one respondent, "time when they do not have to think about anything". An explicitly indicated desire for mental rest also makes smartphones, we believe, tools for maintaining the well-being of the students researched.

\section{Shortcomings and Future Research Directions}

The limitation of the research is its topicality, which can be recognized only in a group of high school students from various schools in central Slovak Republic ( $\mathrm{n}=90)$, although the basic categories of research were formulated among high school students from the whole of Slovak Republic $(n=20)$, i.e., from a small country in Eastern Europe that will soon (in November) commemorate 32 years of its freedom after the end of the communist regime.

The partial self-explanatory nature of the methodologies used is a limit of the paper, which may have caused some distortion of the results. Due to the limited scope of the study, the authors did not compare the findings based, for example, on gender, or the academic achievements of the students. The research would certainly be enriched by the mutual correlations of the findings based on both criteria.

A suitable addition to the findings would also be a research sample of university students and a mutual comparison of findings in both age groups. Despite the shortcomings indicated, we consider this research into tools for sustaining the well-being of Slovak high school students during the COVID-19 pandemic to be beneficial, precisely because of the rapid changes and trends that occurred in connection with the pandemic, and to which the young generation responds most quickly.

The cognitive value of the research is the presentation of the main emphasis of the issues we researched regarding the use of SM as a tool for sustaining the well-being of high school students from Slovak Republic during the COVID-19 pandemic, and also the presentation of relevant research. Related literature and empirical studies confirm that, in the contemporary young generation, the influence of SM on perception of well-being is proving to be ambiguous, and their use can be both advantageous [39,40,54-57] and harmful [58-63] for mental well-being. 
On the other hand, more negative effects can be seen among the research findings because a number of scholars emphasize the risks and negative effects of the use of SM on well-being [39,40,52,54-57]. In the context of primarily negative effects of the use of SM on well-being, our study empirically proves that Slovak high school students' participation in online life directly correlates to their online involvement, including student's involvement in order to strengthen their virtual participation in building well-being.

\section{Conclusions}

Attempts are currently being made to understand the nature of the many consequences of the COVID-19 pandemic. Research efforts are primarily in connection with mental health and the consequences (e.g., fear, depression, or isolation) that this situation has caused in society and in the lives of specific individuals $[103,104]$. The fact remains that in conditions of isolation, lifestyle changes are necessary. Lockdown is a lightning-fast, visible, and tangible change, holding out hope for its ending. In turn, the increase in the use of SM during the pandemic brings rather intense and unstoppable changes and habits that have an impact on an individual and their well-being.

The question of how media use affects the well-being of young media users has been a subject of recent and current attention from a number of scholars. Briefly, experts today have no doubt about the multiple impacts of SM on an individual's well-being and lifestyle [16-22], as well as on peoples' social behaviour [23-26]. Related literature and mentioned empirical evidence confirm the ambiguous influence of SM on young people's perceptions of well-being. Thus, the relationship between SM use and the well-being of young people remains controversial to this day, and research on this issue is faced with numerous challenges.

The aim of our research was to study the use of SM as a tool in sustaining the wellbeing of high school students during COVID-19; to meet this goal, we gathered data from 20 respondents in pre-research (by the use of the structured interview method) and 90 respondents in the main research (by the use of a questionnaire). Through the questionnaire, we could map the five research areas based on the opinions of high school students, which resulted in several interesting findings.

The results indicated that the use of SM as a tool that contributes to the well-being of the respondents during the pandemic is especially relevant when SM (1) supports the personal interests of the respondents; (2) was used as a tool for increasing motivation; (3) was used as a tool for connecting and reconnecting with other people (i.e., communication and interpersonal connectivity); (4) was used as a tool in using preferred components of online study; and (5) was used as a tool for entertainment. Information from our research might be considered as relevant to concerns about young people and their online lives.

The specific findings concerning the interests of Slovak students during the pandemic are considered valuable to the Slovak local authorities. In response to the primarily negative effects of the use of SM on well-being, the cognitive value of this article can be considered as a set of recommendations regarding the use of SM as a tool in sustaining Slovak high school students' well-being during the pandemic. The study further empirically proves that Slovak students' participation in online life directly correlates to their involvement online, including involvement in order to strengthen their virtual participation in building well-being. These findings correspond with the research findings of Cleave et al. [53], which suggest that we should treat students as very active and relevant stakeholders, and strengthen - as well as encourage-their participation by stimulating a feeling of co-responsibility for human well-being in the contemporary online environment. This is a challenge that applies not only to schools or teachers, as bearers of certain values and important creators of norms that form youth who are subject to their influence [97], but also to other authorities, such as managers, employers, supervisors, municipalities, policy makers, governments, and others.

Related literature and relevant research, as well as our own research findings, confirm that the use of SM by young people in Slovak Republic is now an unstoppable phenomenon, 
which has negative but also positive consequences for their well-being. To understand these changes, a broader awareness of the ways in which SM is used and the implications of SM for well-being in this still vulnerable audience is needed. Finding those ways and constantly updating the findings (due to rapid changes that determine the character of the young generation) can help parents, educators, caretakers, policy makers, and others to better identify and respond to the SM that young people use on a daily basis when sitting in front of their computers.

In this vein, in the context of the related literature and our own research, we summarize our various findings.

The following observations for the management of SM by schools, managers, employers, non-profit youth organizations, policy makers etc., during the COVID-19 crisis might be useful:

(1) The qualitative results obtained through structured interviews in our research indicate students' motivation and joy in sharing popular ideas or activities during a pandemic, so that "other people can be inspired." Young Slovaks stated that they wrote personal messages and created statuses, as they gave others the feeling that during lockdown they "experience the same as others" or "that in this (pandemic) no one is alone." Thus, we can see significant activities of the research students in favour of also building well-being in the online environment [14], where respondents feel part of online culture, i.e., "participatory culture" [16].

(2) The high school students researched use SM as an interactive tool to support their personal interests. However, this hardly corresponds to the current use of SM as a promotional tool for economic development at the municipal level through marketing or branding. Briefly, SM is basically used as a tool to promote local services, political information, or advertising [53]. The positive effects (as well as discovering new positive effects) of SM on people and their well-being are very limited.

(3) There seems to be a certain misunderstanding of the rich possibilities of SM, which is not used as a preventive element in different cases. On the contrary, SM is mostly used only as a live information channel through which information is delivered to the public $[28,65]$. Therefore, the active use of social networks, web portals, and other interactive platforms is welcome, not only to inform the audience, but also to foster interaction, dialogue, and relationships with the audience. Our research findings correlate, inter alia, with the research findings of Lee and Ma. [74].

(4) In our research area, named as "communication and interpersonal connectivity sustainable by using the SM during pandemic", several SM communication tools were identified; for example, virtual communities, newsgroups, chat, social networks' closed groups, etc. We consider these online places as places where various discussions about various things take place. Here may be an interesting way that social media management utilizes "user-generated content"; for example, in the context of the brand management of businesses or services. At present, it is repeatedly confirmed that SM is becoming an excellent tool for brand management [105], because a growing SM audience is one of the best ways to enhance service loyalty [106], brand performance [107], and brand management [108]. It is also a great tool to spread brand awareness, including B2B forms (where businesses provide professional advice to their business peers through $\mathrm{SM}$ ) as well as in $\mathrm{B} 2 \mathrm{C}$ form (where companies provide social customer care through SM). User-generated content is about brand building, brand communication, and trust building, which also has an effect on the satisfaction of people (i.e., current and potential customers) and their well-being.

(5) Because young SM users in our research sample are a significant part of the online environment, they are willingly involved in creating web content. Our findings correspond to the conclusions of research conducted by experts [14,16,106-108]. There is a current need to thoroughly investigate how we can use SM as a tool to actively sensitize people [28] to being proactive in the prevention of pandemic-related worries, which influence people's mental health and well-being. The pertinent question 
appears to be: how might governments, municipalities, non-profit organizations, industries, policy makers, or schools motivate the general public, employees, and students to manage and surpass current reactive and informative social-media management in order to proactively strengthen the use of SM in favour of building and promoting a healthy lifestyle and personal well-being?

(1) During the COVID-19 pandemic, changes were reported in SM use and people's health behaviour [43-45], and particularly mental health behaviours [33,46,47]. Although the subjects of this research are purely different, they have a common denominator, which is the emphasis on the implementation of psychological support systems during the pandemic.

Author Contributions: Conceptualization, H.T.; methodology, H.T., Z.J. and P.M.; validation, H.T.; M.P. and R.K.; formal analysis, H.T.; investigation, H.T.; M.P. and R.K.; resources, Z.J. and P.M.; data curation, H.T.; M.P.; Z.J.; P.M. and R.K.; writing—original draft preparation, H.T.; writing-review and editing, H.T., Z.J.; R.K.; visualization, H.T.; M.P. and P.M; and supervision, P.M. and R.K. All authors have read and agreed to the published version of the manuscript.

Funding: This work was supported by the Cultural and Educational Grant Agency (KEGA) of the Ministry of Education, Science, Research and Sports of the Slovak Republic based on project "Implementation of e-learning in the chemistry education for applied ecology and environmental science", number 029UKF-4/2020 and by the project "Perspectives of Contemporary Religiosity Development in Slovakia", which was realized with the support of the Slovak Research and Development Agency under the contract No. APVV-17-0158.

Institutional Review Board Statement: Not applicable.

Informed Consent Statement: Not applicable.

Data Availability Statement: The data presented in this study are available from the authors upon request.

Conflicts of Interest: The authors declare no conflict of interest.

\section{References}

1. Tsao, S.F.; Chen, H.; Tisseverasinghe, T.; Yang, Y.; Lianghua, L.; Butt, Z. A What social media told us in the time of COVID-19: A scoping review. Lancet. Digit. Health 2021, 3, 175-194. [CrossRef]

2. Venegas-Vera, A.; Colbert, G.B.; Lerma, E.V. Positive and negative impact of social media in the COVID-19 era. Rev. Cardiovasc. Med. 2020, 21, 561-564. [CrossRef]

3. Nguyen, M.H.; Gruber, J.; Fuchs, J.; Marler, W.; Hunsaker, A.; Hargittai, E. Changes in Digital Communication During the COVID-19 Global Pandemic: Implications for Digital Inequality and Future Research. Soc. Media Soc. 2020, 6. [CrossRef]

4. Rončáková, T. Closed Churches during the Pandemic: Liberal versus Conservative and Christian versus Atheist Argumentation in Media. J. Media 2021, 2, 225-243.

5. Baym, N.K. Personal Connections in the Digital Age; John Wiley \& Sons: Hoboken, New Jersey, USA, 2015.

6. Blekesaune, A.; Elvestad, E.; Aalberg, T. Tuning out the world of news and current affairs-An empirical study of Europe's disconnected citizens. Eur. Sociol. Rev. 2010, 28, 110-126. [CrossRef]

7. Petrovič, F.; Murgaš, F. Linking sustainability and happiness. What kind of happiness? GeoScape 2020, 14, 70-79. [CrossRef]

8. Parker, P.; Igielnik, R. On the Cusp of Adulthood and Facing an Uncertain Future: What We Know About Gen Z So Far. Available online: https:/ / www.pewresearch.org/social-trends/2020/05/14/on-the-cusp-of-adulthood-and-facing-an-uncertain-futurewhat-we-know-about-gen-z-so-far-2/ (accessed on 20 June 2021).

9. Pempek, T.A.; Yermolayeva, Y.A.; Calvert, S.L. College students' social networking experiences on facebook. J. Appl. Dev. Psychol. 2009, 30, 227-238. [CrossRef]

10. Lenhart, A.; Purcell, L.; Smith, A.; Zickuhr, K. Social Media and Young Adults. Available online: http:/ / samaritanbehavioralhealth. net/files/social-media-young-adults.pdf (accessed on 23 June 2021).

11. Internet and American Life Project. Available online: https://www.pewresearch.org/internet/2010/02/03/social-media-andyoung-adults / (accessed on 23 July 2021).

12. Malhotra, A.; Totti, L.; Meira, W.; Kumaraguru, P., Jr.; Almeida, V. Studying User Footprints in Different Online Social Networks. In Proceedings of the 2012 International Conference on Advances in Social Networks Analysis and Mining, Istanbul, Turkey, 26-29 August 2012; pp. 1065-1070. [CrossRef]

13. Birdsall, W.F. Web 2.0 as a Social Movement. Webology 2007, 4, 1-13.

14. Beer, D.; Burrows, R. Sociology and of and in Web 2.0: Some initial considerations. Sociol. Res. 2007, 12, 67-79. [CrossRef] 
15. Kaplan, A.M.; Haenlein, M. Users of the world, unite! The challenges and opportunities of Social Media. Bus. Horiz. 2010, 53, 59-68. [CrossRef]

16. Jenkins, H. Fans, Bloggers, and Gamers: Exploring Participatory Culture; New York University Press books: New York, NY, USA, 2006.

17. Consolvo, S.; McDonald, D.W.; Landay, J. Theory-Driven Design Strategies for Technologies that Support Behavior Change in Everyday Life. In Proceedings of the SIGCHI Conference on Human Factors in Computing Systems, Boston, MA, USA, 4-9 April 2009; pp. 405-414.

18. Khan, S. Impact of social networking websites on students. Abasyn J. Soc. Sci. 2012, 5, 56-77.

19. Chukwuere, J.E.; Chukwuere, P.C. The impact of social media on social lifestyle: A case study of university female students. Gend. Behav. 2017, 15, 9966-9981. [CrossRef]

20. Hargittai, E. Whose space? Differences among users and non-users of social network sites. J. Comput. Mediat. Commun. 2007, 13, 276-297. [CrossRef]

21. Strømme, H.; Mosdøl, A.; Nordheim, L.W.; Vist, G.E. Effects of Using Social Media in Health Awareness Campaigns to Promote Healthy Lifestyle Habits; Knowledge Centre for the Health Services at The Norwegian Institute of Public Health: Oslo, Norway, 2018.

22. Korda, H.; Itani, Z. Harnessing social media for health promotion and behavior change. Health Promot. Pract. 2011, 14, 15-23. [CrossRef] [PubMed]

23. Crilly, P.; Hassanali, W.; Khanna, G.; Matharu, K.; Patel, D.; Patel, D.; Rahman, F.; Kayyali, R. Community pharmacist perceptions of their role and the use of social media and mobile health applications as tools in public health. Res. Soc. Adm. Pharm. 2019, 15, 23-30. [CrossRef] [PubMed]

24. Al-Sharqi, L.; Hashim, K.; Kutbi, I. Perceptions of social media impact comparison between arts and science students. Int. J. Educ. Soc. Sci. 2015, 2, 122-131. [CrossRef]

25. Schrammel, J.; Koffel, C.; Tscheligi, M. How much do you tell? Information disclosure behaviour in different types of online communities. In Proceedings of the Fourth International Conference on Communities and Technologies, University Park, PA, USA, 25-27 June 2009; pp. 279-284. [CrossRef]

26. Rajeev, M.M. Effects of Social Media on Social Relationships: A Descriptive Study on the Impact of Mobile Phones among Youth Population. Int. Res. J. Soc. Sci. 2015, 4, 11-16.

27. Burke, M.; Kraut, R. Growing closer on Facebook?: Changes in tie strength through social network site use. In In Proceedings of the SIGCHI Conference on Human Factors in Computing Systems, Toronto, ON, Canada, 26 April-1 May 2014; pp. 4187-4196. [CrossRef]

28. Zamarreño-Aramendia, G.; Cristòfol, F.J.; de-San-Eugenio-Vela, J.; Ginesta, X. Social-Media Analysis for Disaster Prevention: Forest Fire in Artenara and Valleseco, Canary Islands. J. Open Innov. Technol. Market. Complex. 2020, 6, 169. [CrossRef]

29. Afsar, B. The relation between Internet and social media use and the demographic and clinical parameters, quality of life, depression, cognitive function and sleep quality in hemodialysis patients: Social media and hemodialysis. Gen. Hosp. Psychiatry 2013, 35, 625-630. [CrossRef]

30. Chen, H.-T.; Li, X. The contribution of mobile social media to social capital and psychological well-being: Examining the role of communicative use, friending and self-disclosure. Comput. Hum. Behav. 2017, 75, 958-965. [CrossRef]

31. Goodyear, V.A.; Boardley, I.; Chiou, S.Y.; Fenton, S.A.M.; Makopoulou, K.; Stathi, A.; Wallis, G.A.; Veldhuijzen van Zanten, J.C.S.; Thompson, L.J. Social media use informing behaviour related to physical activity, diet and quality of life during COVID-19: A mixed methods study. BMC Public Health 2021, 21, 1333. [CrossRef]

32. Ellison, N.B.; Boyd, D. Sociality through Social Network Sites. In The Oxford Handbook of Internet Studies; Dutton, W.H., Ed.; Oxford University Press: Oxford, UK, 2013; pp. 151-172.

33. Ellison, N.B.; Steinfield, C.; Lampe, C. The benefits of Facebook "friends:" Social capitol and college students' use of online social network sites. J. Comput. Mediat. Commun. 2007, 12, 1143-1168. [CrossRef]

34. Lampinen, A.; Tamminen, S.; Oulasvirta, A. All my people right here, right now: Management of group co-presence on a social networking site. In Proceedings of the ACM 2009 International Conference on Supporting Group Work, Sanibel Island, FL, USA, 10-13 May 2009; pp. 281-290. [CrossRef]

35. Hogan, B. The presentation of self in the age of social media: Distinguishing performances and exhibitions online. Bull. Sci. Technol. Soc. 2010, 30, 377-386. [CrossRef]

36. Joinson, A.N. Looking at, looking up or keeping up with people? Motives and use of Facebook. In In Proceedings of the Conference on Human Factors in Computing Systems, Florence, Italy, 5-10 April 2008; pp. 1027-1036. [CrossRef]

37. Kim, B.; Kim, Y. Facebook versus Instagram: How perceived gratifications and technological attributes are related to the change in social media usage. Soc. Sci. J. 2019, 56, 156-167. [CrossRef]

38. Best, P.; Manktelow, R.; Taylor, B. Online communication, social media and adolescent well-being: A systematic narrative review. Child. Youth Serv. Rev. 2014, 41, 27-36. [CrossRef]

39. Holsten, H.H. How does social media affect your well-being? Available online: https:/ / partner.sciencenorway.no/forskningnonorway-partner/how-does-social-media-affect-your-well-being/1454613 (accessed on 26 June 2021).

40. Brown, J.D.; Bobkowski, P.S. Older and Newer Media: Patterns of Use and Effects on Adolescents' Health and Well-Being. J. Res. Adolesc. 2011, 21, 95-113. [CrossRef]

41. O'Reilly, M.; Dogra, N.; Whiteman, N.; Hughes, J.; Eruyar, S.; Reilly, P. Is social media bad for mental health and well-being? Exploring the perspectives of adolescents. Clin. Child. Psychol. Psychiatry 2018, 23, 601-613. [CrossRef] 
42. Bekalu; McCloud, R.F.; Viswanath, K. Association of social media use with social well-being, positive mental health, and self-rated health: Disentangling routine use from emotional connection to use. Health Educ. Behav. 2019, 46, 69-80. [CrossRef]

43. Naughton, F.; Ward, E.; Khondoker, M.; Belderson, P.; Minihane, A.M.; Dainty, J.; Hanson, S.; Holland, R.; Brown, T.; Notley, C. Health behaviour change during the UK COVID-19 lockdown: Findings from the first wave of the C-19 health behaviour and well-being daily tracker study. Br. Psychol. Soc. 2021, 26, 624-643. [CrossRef]

44. Onuora, C.; Obasi, M.T.; Ezeahet, G.H.; Gever, V.C. Effect of dramatized health messages: Modelling predictors of the impact of COVID-19 YouTube animated cartoons on health behaviour of social media users in Nigeria. Int. Sociol. 2020, 36, 124-140. [CrossRef]

45. Chavarría, E.; Diba, F.; Marcus, M.E.; Marthoenis, R.A.; Rogge, L.; Vollmer, S. Knowing Versus Doing: Protective Health Behavior Against COVID-19 in Aceh, Indonesia. J. Dev. Stud. 2021, 57, 1245-1266. [CrossRef]

46. Naeem, M. Do social media platforms develop consumer panic buying during the fear of Covid-19 pandemic. J. Retail. Consum. Serv. 2021, 58, 102226. [CrossRef]

47. Arora, T.; Grey, I. Health behaviour changes during COVID-19 and the potential consequences: A mini-review. J. Health Psychol. 2020, 25, 1155-1163. [CrossRef]

48. Gadušová, Z.; Jakubovská, V.; Markechová, D.; Tirpáková, A. Teacher competences development-A guarantee of sustainable high level of education and training. TEM J. 2019, 8, 1063-1070. [CrossRef]

49. Kobylarek, A. Post-pandemic challenges for learning communities. J. Educ. Cult. Soc. 2021, 12, 5-11. [CrossRef]

50. Swist, T.; Collin, P.; McCormack, J.; Third, A. Social Media and the Well-Being of Children and Young People: A Literature Review; Western Sydney University: Penrith, NSW, Australia, 2015.

51. McDool, E.; Powell, P.; Roberts, J.; Taylor, K.B. Social Media Use and Children's Well-being. IZA Discussion Paper No. 10412. Available online: https:/ / ssrn.com/abstract=2886783 (accessed on 20 June 2021).

52. Shakya, H.B.; Christakis, N.A. Association of Facebook use with compromised well-being: A longitudinal study. Am. J. Epidemiol. 2017, 185, 203-211. [CrossRef] [PubMed]

53. Cleave, E.; Arku, G.; Sadler, R.; Kyeremeh, E. Place Marketing, Place Branding, and Social Media: Perspectives of Municipal Practitioners. Growth Chang. A J. Urban. Reg. Policy 2017, 48, 1012-1033. [CrossRef]

54. Woods, H.C.; Scott, H. \#Sleepyteens: Social media use in adolescence is associated with poor sleep quality, anxiety, depression and low self-esteem. J. Adolesc. 2016, 51, 41-49. [CrossRef]

55. Kross, E.; Verduyn, P.; Demiralp, E.; Park, J.; Seungjae Lee, D.; Lin, N.; Shablack, H.; Jonides, J.; Ybarra, O. Facebook use predicts declines in subjective well-being in young adults. PLoS ONE 2013, 8, e6984. [CrossRef]

56. Ra, C.K.; Cho, J.; Stone, M.D.; De La Cerda, J.; Goldenson, N.I.; Moroney, E.; Leventhal, A.M. Association of digital media use with subsequent symptoms of attention-deficit/hyperactivity disorder among adolescents. JAMA J. Am. Med Assoc. 2018, 320, 255-263. [CrossRef]

57. Frison, E.; Eggermont, S. Toward an integrated and differential approach to the relationships between loneliness, different types of Facebook use, and adolescents' depressed mood. Commun. Res. 2015, 47, 701-728. [CrossRef]

58. Özdemir, Y.; Kuzucu, Y.; Ak, Ş. Depression, loneliness and Internet addiction: How important is low self-control? Comput. Hum. Behav. 2014, 34, 284-290. [CrossRef]

59. Allen, K.; Ryan, T.; Gray, D.; McInerney, D.; Waters, L. Social Media Use and Social Connectedness in Adolescents: The Positives and the Potential Pitfalls. Aust. Educ. Dev. Psychol. 2014, 31, 18-31. [CrossRef]

60. Steinfield, C.; Ellison, N.B.; Lampe, C. Social capital, self-esteem, and use of online social network sites: A longitudinal analysis. J. Appl. Dev. Psychol. 2008, 29, 434-445. [CrossRef]

61. Kawachi, I.; Subramanian, A.; Kim, D. Social Capital and Health; Springer: New York, NY, USA, 2008.

62. Kim, B.; Kim, Y. College students' social media use and communication network heterogeneity: Implications for social capital and subjective well-being. Comput. Hum. Behav. 2017, 73, 620-628. [CrossRef]

63. Valenzuela, S.; Park, N.; Kee, K.F. Is there social capital in a social network site? Facebook use and college student's life satisfaction, trust, and participation. J. Comput. Mediat. Commun. 2009, 14, 875-901. [CrossRef]

64. Nabi, R.L.; Prestin, A.; So, J. Facebook friends with (health) benefits? Exploring social network site use and perceptions of social support, stress, and well-being. Cyberpsychology Behav. Soc. Netw. 2013, 16, 721-727. [CrossRef] [PubMed]

65. Cachia, R.; Compañó, R.; Da Costa, O. Grasping the potential of online social networks for foresight. Technol. Forecast. Soc. Chang. 2007, 74, 1179-1203. [CrossRef]

66. Wang, Y.; Zhao, X.; Feng, Q.; Liu, L.; Yao, Y.; Shi, J. Psychological assistance during the coronavirus disease 2019 outbreak in China. J. Health Psychol. 2020, 25, 733-737. [CrossRef]

67. Zaka, A.; Shamloo, S.E.; Fiorente, P.; Tafuri, A. COVID-19 pandemic as a watershed moment: A call for systematic psychological health care for frontline medical staff. J. Health Psychol. 2020, 25, 883-887. [CrossRef]

68. Zhou, J.; Liu, L.; Xue, P.; Tang, X. Mental health response to the COVID-19 outbreak in China. Am. J. Psychiatry 2020, 177, 574-575. [CrossRef]

69. Robinson, L.; Smith, M. Social Media and Mental Health. Available online: https://www.helpguide.org/articles/mental-health/ social-media-and-mental-health.htm\# (accessed on 22 July 2021).

70. Wathelet, M.; Duhem, S.; Vaiva, G. Factors associated with mental health disorders among university students in France confined during the COVID-19 pandemic. JAMA Netw. Open. 2020, 3, e2025591. [CrossRef] [PubMed] 
71. Smyk, A. Dynamic Storytelling: The Rebirth of Multimedia Experiences. Available online: https://blog.adobe.com/en/publish/ 2017/01/17/dynamic-storytelling-the-rebirth-of-multimedia-experiences.html\#gs.3fl6w6 (accessed on 19 May 2021).

72. Musil, J. Elektronická Médiá v Informační Společnosti [Electronic Media in the Information Society]; Votobia: Praha, Czech Republic, 2003.

73. Lee, C.S.; Ma, L. News sharing in social media: The effect of gratifications and prior experience. Comput. Hum. Behav. 2012, 28, 331-339. [CrossRef]

74. Neal, D.T.; Wood, W.; Quinn, J.M. Habits A Repeat Performance. Curr. Dir. Psychol. Sci. 2006, 15, 198-202. [CrossRef]

75. Das Swain, D.; Saha, K.; Abowd, G.D.; De Choudhury, M. Social Media and Ubiquitous Technologies for Remote Worker Well-being and Productivity in a Post-Pandemic World. In Proceedings of the IEEE Second International Conference on Cognitive Machine Intelligence, Virtual Conference, 1-3 December 2020; pp. 121-130. [CrossRef]

76. Al-Kumaim, N.H.; Alhazmi, A.K.; Mohammed, F.; Gazem, N.A.; Shabbir, M.S.; Fazea, Y. Exploring the Impact of the COVID-19 Pandemic on University Students' Learning Life: An Integrated Conceptual Motivational Model for Sustainable and Healthy Online Learning. Sustainability 2021, 13, 2546. [CrossRef]

77. Zacher, H.; Rudolph, C.W. Individual differences and changes in subjective well-being during the early stages of the COVID-19 pandemic. Am. Psychol. 2021, 76, 50-62. [CrossRef] [PubMed]

78. Alexander, E.S.; Onwuegbuzie, A.J. Academic procrastination and the role of hope as a coping strategy. Personal. Individ. Differ. 2007, 42, 1301-1310. [CrossRef]

79. Swaraswati, Y.; Winarno, A.R.D.; Goeritno, G. Academic procrastination of undergraduate students: The role of academic self-efficacy and the big five personality traits. In Proceedings of the 9th International Conference for Science Educators and Teachers, Semarang, Indonesia, 13-15 September 2017; pp. 735-740. [CrossRef]

80. Asri, N.D.; Setyosari, P.; Hitipeuw, I.; Chusniyah, T. The Influence of Project-based Learning Strategy and Self-regulated Learning on Academic Procrastination of Junior High School Students' Mathematics Learning. Am. J. Educ. Res. 2017, 5, 88-96. [CrossRef]

81. Joubert, C.P. The Relationship between Procrastination and Academic Achievement of High School Learners in North West province, South Africa. Ph.D. Thesis, University of South Africa, Pretoria, South Africa, 2015.

82. Karatas, H. Correlation among academic procrastination, personality traits, and academic achievement. Anthropologist 2015, 20, 243-255. [CrossRef]

83. Zakeri, H.; Esfahani, B.N.; Razmjoee, M. Parenting Styles and Academic Procrastination. Procedia Soc. Behav. Sci. 2013, 84, 57-60. [CrossRef]

84. Motie, H.; Heidari, M.; Sadeghi, M. Predicting Academic Procrastination during Self-Regulated Learning in Iranian first Grade High School Students. Procedia Soc. Behav. Sci. 2012, 69, 2299-2308. [CrossRef]

85. Chu, A.; Choi, J.N. Rethinking procrastination: Positive effects of "active" procrastination behavior on attitudes and performance. J. Soc. Psychol. 2005, 145, 245-264. [CrossRef] [PubMed]

86. Steel, P. The nature of procrastination: A meta-analytic and theoretical review of quintessential self-regulatory failure. Psychol. Bull. 2007, 133, 65-94. [CrossRef] [PubMed]

87. Beck, B.L.; Koons, S.R.; Milgram, D.L. Correlates and consequences of behavioral procrastination: The effects of academic procrastination, self-consciousness, self-esteem, and self-handicapping. J. Soc. Behav. Personal. 2000, 15, 3-13.

88. Rosário, P.; Costa, M.; Núñez, J.; González-Pienda, J.; Solano, P.; Valle, A. Academic Procrastination: Associations with Personal, School, and Family Variables. Span. J. Psychol. 2009, 12, 118-127. [CrossRef] [PubMed]

89. Tice, D.M.; Baumeister, R.F. Longitudinal Study of Procrastination, Performance, Stress, and Health: The Costs and Benefits of Dawdling. Psychol. Sci. 1997, 8, 454-458. [CrossRef]

90. Silver, M.; Sabini, J. Procrastinating. J. Theory Soc. Behav. 1981, 11, 207-221. [CrossRef]

91. Murphy, L. 'Why am I doing this?' Maintaining motivation in distance language learning. In Identity, Motivation and Autonomy in Language Learning; Murray, G., Gao, X., Lamb, T., Eds.; Multilingual matters: Bristol, Buffalo, Toronto, 2011 ; pp. 107-122.

92. Senécal, C.; Koestner, R.; Vallerand, R.J. Self-Regulation and Academic Procrastination. J. Soc. Psychol. 1995, 135, 607-619. [CrossRef]

93. Canale, N.; Marino, C.; Lenzi, M.; Vieno, A.; Griffiths, M.; Gaboardi, M.; Cervone, C.; Santinello, M. How communication technology helps mitigating the impact of COVID-19 pandemic on individual and social well-being: Preliminary support for a compensatory social interaction model. PsyArXiv 2020, 1-21. [CrossRef]

94. Donath, J.; Boyd, D. Public Displays of Connection. BT Technol. J. 2004, 22, 71-82. [CrossRef]

95. Quan-Haase, A.; Young, A.L. Uses and gratifications of social media: A comparison of facebook and instant messaging. Bull. Sci. Technol. Soc. 2010, 30, 350-361. [CrossRef]

96. Tvrdoň, M.; Kondrla, P.; Mesárošová, L. Social work as a tool for anomie correction on second stage of primary school. Ad. Alta J. Interdiscip. Res. 2021, 11, 353-357.

97. Noor Al-Deen, H.S.; Hendricks, J.A. Social Media: Usage and Impact; Lexington Books: Lanham, MD, USA, 2012.

98. Beavis, C.; Charles, C. Writing, English and digital culture. In Writing-Learning; Doecke, B., Parr, G.P., Eds.; Wakefield Press: Kent Town, Australia, 2005; pp. 229-246.

99. Beavis, C.; Apperley, T.; Bradford, C.; O’Mara, J.; Walsh, C.H. Literacy in the digital age: Learning from computer games. Engl. Educ. 2009, 43, 162-175. [CrossRef]

100. Walsh, C.H.S.; Kamler, B. Teacher Research on Literacy: Turning Around to Students and Technology. In International Handbook of Research on Children's Literacy, Learning, and Culture; Hall, K., Cremin, T., Comber, B., Moll, L.C., Eds.; John Wiley \& Sons Ltd.: Indianapolis, IN, USA, 2013; pp. 499-513. 
101. Apperley, T.; Walsh, C.H. What digital games and literacy have in common: A heuristic for understanding pupils' gaming literacy. Literacy 2012, 46, 115-122. [CrossRef]

102. Lufkin, B. Gamers Have Known for a Long Time Something that Everyone Else is Starting to Figure Out: There's Community Connection on the Other Side of a Screen. Available online: https://www.bbc.com/worklife/article/20201215-how-onlinegaming-has-become-a-social-lifeline (accessed on 23 June 2021).

103. Li, W.; Yang, Y.; Liu, Z.H.; Zhao, Y.J.; Zhang, Q.; Zhang, L.; Cheung, T.; Xiang, Y.T. Progression of mental health services during the COVID-19 outbreak in China. Int. J. Biol. Sci. 2020, 16, 1732-1738. [CrossRef]

104. Holmes, E.A.; O'Connor, R.C.; Perry, V.H.; Tracey, I.; Wessely, S.; Arseneault, L.; Ballard, C.; Christensen, H.; Silver, R.C.; Everall, I. Multidisciplinary research priorities for the COVID-19 pandemic: A call for action for mental health science. Lancet Psychiatry 2020, 7, 547-560. [CrossRef]

105. So, K.K.F.; Wu, L.; Xiong, L.; King, C. Brand Management in the Era of Social Media: Social Visibility of Consumption and Customer Brand Identification. J. Travel Res. 2017, 57, 727-742. [CrossRef]

106. Ashraf, S. How The World's Top 7 Airlines Use Social Media-Business 2. Community. Available online: https://www.business2 community (accessed on 6 September 2021).

107. Gensler, S.; Völckner, F.; Liu-Thompkins, Y.; Wiertz, C. Managing Brands in the Social Media Environment. J. Interact. Mark. 2013, 2, 242-256. [CrossRef]

108. Botha, E.; Mills, A.J. Managing new Media: Tools for Brand Management in Social Media. In Online Consumer Behavior: Theory and Research in Social Media, Advertising and E-tail; Scheinbaum, A.C., Ed.; Routledge: New York, NY, USA, 2012; pp. 1-18. 